\title{
Integrated assessment of marine biodiversity status using a prototype indicator-based assessment tool
}

\author{
Jesper H. Andersen 1,2*, Karsten Dahl ${ }^{3}$, Cordula Göke ${ }^{3}$, Martin Hartvig ${ }^{4,5}$, Ciarán Murray ${ }^{3}$, \\ Anna Rindorf ${ }^{4}$, Henrik Skov ${ }^{6}$, Morten Vinther $^{4}$ and Samuli Korpinen ${ }^{2}$ \\ NIVA Denmark Water Research, Copenhagen, Denmark \\ ${ }^{2}$ Marine Research Center, Finnish Environment Institute (SYKE), Helsinki, Finland \\ ${ }^{3}$ Department of Bioscience, Aarhus University, Roskilde, Denmark \\ ${ }^{4}$ DTU Aqua, Section for Marine Ecosystem-Based Management, Technical University of Denmark, Charlottenlund, Denmark \\ ${ }^{5}$ Centre for Macroecology, Evolution and Climate, University of Copenhagen, Copenhagen, Denmark \\ ${ }^{6}$ DHI, Hørsholm, Denmark
}

\section{Edited by:}

Christos Dimitrios Arvanitidis, Hellenic Centre for Marine

Research, Greece

\section{Reviewed by:}

Christos Dimitrios Arvanitidis,

Hellenic Centre for Marine

Research, Greece

Marco Sigovini, National Research

Council of Italy, Italy

Céline Labrune, Centre National de

la Recherche Scientifique, France

*Correspondence:

Jesper H. Andersen, NIVA Denmark

Water Research, Ørestads

Boulevard 73, 2300 Copenhagen S,

Denmark

e-mail: jha@niva-danmark.dk
Integrated assessment of the status of marine biodiversity is and has been problematic compared to, for example, assessments of eutrophication and contamination status, mostly as a consequence of the fact that monitoring of marine habitats, communities and species is expensive, often collected at an incorrect spatial scale and/or poorly integrated with existing marine environmental monitoring efforts. The objective of this Method Paper is to introduce and describe a simple tool for integrated assessment of biodiversity status based on the HELCOM Biodiversity Assessment Tool (BEAT), where interim biodiversity indicators are grouped by themes: broad-scale habitats, communities, and species as well as supporting non-biodiversity indicators. Further, we report the application of an initial indicator-based assessment of biodiversity status of Danish marine waters where we have tentatively classified the biodiversity status of Danish marine waters. The biodiversity status was in no areas classified as "unaffected by human activities." In all the 22 assessment areas, the status was classified as either "moderately affected by human activities" or "significantly affected by human activities." Spatial variations in the biodiversity status were in general related to the eutrophication status as well as fishing pressure.

Keywords: biodiversity, marine, integrated assessment, habitats, communities, species, Marine Strategy Framework Directive

\section{INTRODUCTION}

Assessments of biological diversity have the ambitious objective of describing the state of an entire ecosystem, often by using only a few selected indicators. The challenge of this objective is to select a representative set of indicators, which fulfill the needs of science and marine policy. The EU Marine Strategy Framework Directive (MSFD) sets 11 qualitative descriptors for "good environmental status" (Anon, 2008), laying a common framework for all European marine biodiversity assessments. In this new assessment regime, biodiversity is considered to include not only the species diversity and the state of populations and habitats, but also seafloor integrity and food webs. Despite the detailed guidance on the selection of indicators (Anon, 2010), the MSFD does not provide a methodology to assess the overall state of marine ecosystems with the proposed criteria and indicators. Instead the EC tasked ICES with the production of detailed reports on the next steps of the implementation of the MSFD descriptors (see Cardoso et al., 2010 and relevant background reports).

Biodiversity assessments generally need to take into account the fact that marine biodiversity is sensitive to and also structured by natural factors such as salinity, currents, temperature, etc. More specifically, marine biodiversity assessments have been limited by the lack of integrated monitoring networks, highquality biodiversity indicators, and indicator-based assessment tools (Borja, 2014), partly a consequence of the vast nature of biodiversity. We hypothesize that all three deficiencies are related to two shortcomings in monitoring. Firstly, monitoring of marine biodiversity is often expensive compared to the monitoring of eutrophication and contamination and good proxies for biodiversity changes have not been developed. Secondly, for certain features of marine biodiversity, e.g., seabirds, monitoring is inadequately integrated with the existing marine environmental monitoring and, hence, resources are wasted in uncoordinated efforts.

Consequently, assessments of marine biodiversity are not as well-developed as other types of assessments, where multi-metric indicator-based assessment tools are commonly used (HELCOM, 2010; Andersen et al., 2011). The regional sea conventions in the Baltic Sea (HELCOM; www.helcom.fi) and North-East Atlantic (OSPAR; www.ospar.org) as well as EU Directives (Habitats Directive and MSFD) call for assessments of biodiversity, but only HELCOM has thus far made an attempt to develop an prototype indicator-based tool for an assessment of biodiversity (HELCOM, 2009b, 2010). 
A few recent studies of marine biodiversity in Northern Europe are based on data addressing a wide range of biodiversity features (such as phytoplankton, benthic communities, fish, seabirds, marine mammals) and robust and transparent scientific methods, e.g., Certain et al. (2011), Ojaveer et al. (2010), and Ojaveer and Eero (2011). These studies do not, however, take into account numerical biodiversity targets, and this is a shortcoming in regard to assessment of biodiversity status in the context of the MSFD (Anon, 2008).

In this study, we introduce and describe a simple indicatorbased methodology (i.e., tool) for assessing the status of marine biodiversity. The tool is tested in Danish marine waters using provisional indicators with associated numerical target values and the results presented and discussed should accordingly be regarded as tentative. The assessment of biodiversity is made despite the lack of a commonly accepted definition of "marine biodiversity." Both the tool and the assessment are anchored in a Baltic Sea-wide conceptual understanding of "good biodiversity status" (HELCOM, 2010), where the overall vision is a healthy Baltic Sea with a favorable biodiversity status, including (1) natural marine and coastal landscapes, (2) thriving and balanced communities of plants and animals, and (3) viable populations of species. Hence, our understanding of "marine biodiversity" is broad and includes other elements than just a count of the number of species.

\section{METHODS}

We have developed a methodology for classification of "biodiversity status," employing a tool named Biodiversity Assessment Tool (BEAT) 2.0, which is an improved version of the HELCOM Biodiversity Status Assessment Tool (BEAT 1.0). This multimetric indicator-based tool was initially developed for integrated assessment of the status of biodiversity in the Baltic Sea (HELCOM, 2009a, 2010), but its updated version differs from its predecessor by having an improved fit with the EU MSFD descriptors, three status classes, a balanced approach to confidence rating as well as a more user-friendly appearance, where information about the Biodiversity Quality Objective (BQO) as well as interim (per category) and integrated classification results are presented.

BEAT 2.0 is an indicator-based assessment tool. For an individual indicator, synoptic information is required regarding reference conditions (RefCon), acceptable deviation from reference conditions (AcDev), and observations of the present state of biological diversity (Obs). AcDev is defined as a fraction or percentage of the RefCon, and is set site-specifically per indicator.

In calculating the status, we considered two types of indicators: (1) indicators that show a positive (+ve) response to human pressure factors, i.e., whose value increases with greater degradation in biodiversity (e.g., primary production, which is positively correlated to nutrient enrichment), and (2) indicators with a negative (-ve) response, i.e., whose value decreases with greater degradation (e.g., depth distribution of submerged aquatic vegetation, which is negatively correlated to nutrient enrichment or population size of a fish species, which is negatively correlated to fishing pressure).

As a first step, a BQO, which defines the border between "biodiversity status unaffected by human activities" (UN) and "biodiversity status moderately affected by human activities" $(\mathrm{MO})$, is calculated per indicator:

$$
\begin{array}{rlr}
\mathrm{BQO} & =\operatorname{RefCon} \times(1+\mathrm{AcDev}) & (+ \text { ve response }) \\
& =\operatorname{RefCon} \times(1-\mathrm{AcDev}) & (- \text { ve response })
\end{array}
$$

Step 2 is calculating the state value for each indicator through comparison with the BQO to determine indicator status. For example, for an indicator with +ve response, if the observed state (Obs) does not exceed the BQO, then the status "unaffected by human activities" is achieved. If the BQO is exceeded, the status is "moderately" (MO) or "significantly affected by human activities" (SI).

$$
\begin{aligned}
\text { Status } & =\mathrm{UN} & & (+ \text { ve response, Obs } \leq \mathrm{BQO}) \\
& =\mathrm{MO} / \mathrm{SI} & & (+ \text { ve response, Obs }>\mathrm{BQO}) \\
& =\mathrm{UN} & & (- \text { ve response, Obs } \geq \mathrm{BQO}) \\
& =\mathrm{MO} / \mathrm{SI} & & (- \text { ve response, Obs }<\mathrm{BQO})
\end{aligned}
$$

Step 3 is to calculate a Biodiversity Quality Ratio (BQR), which in principle is comparable with the Ecological Quality Ratio principle sensu the WFD (Anon, 2000; Andersen et al., 2011). The BQR approach used in this assessment marks the ratio (0-1) between Obs and RefCon. For indicators with a positive response the BQR is given by RefCon/Obs. For those having a negative response the $\mathrm{BQR}$ is the inverse, i.e., Obs/RefCon.

$$
\begin{aligned}
\mathrm{BQR} & =\text { RefCon/Obs } & (+ \text { ve response }) \\
& =\text { Obs } / \text { RefCon } & (- \text { ve response })
\end{aligned}
$$

This step represents a transformation of indicator-specific information regarding the state of biodiversity to a numerical value, where the BQR values for different indicators can be compared and combined.

As a step 4, indicators are combined within four categories: (I) broad-scale habitats, (II) communities, (III) species, and (IV) supporting indicators. The classifications are based on a weighted average of the $\mathrm{BQO}$ and $\mathrm{BQR}$ values within each category. Weights are established by expert judgment and used to balance indicators among different biodiversity components or correlated indicators (e.g., several fish indicators are down-weighted against single indicators for seabirds or mammals). If not specified otherwise, the weighting is kept neutral by giving each of the indicators equal weights. On the basis of the BQR and AcDev values, each category is given a quantitative assessment according to the principles described above for a single indicator. Individual indicators have only two "classes," i.e., "unaffected" and "impaired/affected." There are three category classes from "unaffected," to "moderately affected" and "significantly affected" by human activities. Whilst the boundary between "unaffected by human activities" (UN) and "moderately affected by human activities" (MO) is a simple weighted average derived from the indicator-specific BQOs, the boundary between "moderately" and "significantly affected by human activities" (SI) is a value of two times the criteria-specific BQO. 
At step 5, the results of the four categories are combined by applying the so-called "One out-All out" principle sensu the Precautionary Principle (MSFD Preamble, section 27; Anon, 2008) to the Categories I-IV. This implies that the category most sensitive to human activities, i.e., scoring lowest, defines the overall status of biodiversity within an assessment sector.

In addition to the above-described classification of biodiversity status, we estimate the confidence of the data and of the resulting classification by applying a simple scoring system (see Andersen et al., 2010). This system was initially developed for estimation of the confidence in eutrophication classifications but can be directly transferred and applied, when assessing biodiversity status. The approach, which scores the data on RefCon, AcDev and Obs gives equal weight to each of these three factors. In order to balance BQOs and Obs, we have modified the weighting of the factors with $25 \%$ to RefCon and AcDev and $50 \%$ to Status. The final confidence of the assessment can range between 100 and $0 \%$ and is according to Andersen et al. (2010) grouped in three classes: High (100-75\%), Acceptable (75-50\%), and Low (<50\%). A description of the confidence rating method is available online as Supporting Material (Annex S3).

All calculations and subsequent classifications are made within a spreadsheet (see the Supplementary Material). Tracking calculations per indicator and also the integrations made per category and integration made in order to arrive at a final classification of biodiversity status is transparent and straightforward.

The BEAT 2.0 tool was tested and demonstrated using data from Danish marine waters, which are located in two distinct marine regions, the saline North Sea and the brackish Baltic Sea (Figure 1). Comprehensive descriptions of the study area and environmental status can be found in HELCOM (2010) and OSPAR (2010). The test was made on the basis of 22 assessment sectors in the Danish marine waters (Figure 1). The assessment sectors were larger in the offshore waters where spatial variation of the biodiversity indicators was considered smaller than in the coastal waters.

The data used for testing of BEAT 2.0 were compiled from various sources. Data on submerged aquatic vegetation as well as plankton (chlorophyll-a), benthic invertebrate communities, and nutrient concentrations originate from the Danish National Aquatic Monitoring and Assessment Programme (DNAMAP; see Conley et al., 2000; Carstensen et al., 2006; Dahl and Carstensen, 2008; Hansen, 2013). Data originates from three sources which are specific to the following areas: (1) offshore parts North Sea, Skagerrak and Kattegat (assessment sectors 1, 2, 4, 5), (2) offshore part of the Arkona Basin and Bornholm Basin, which are parts of the Baltic Sea (sectors 21 and 22), and (3) Danish coastal waters (sectors 3 and 6-20).

The indicators in regard to offshore fish, seabirds and marine mammals, which should be regarded as provisional, were developed specifically for this study and were also used for an interim assessment of biodiversity status in the North Sea (HARMONY project; unpublished data). Indicators used in previous assessments of the state of the North Sea (OSPAR, 2010) and Baltic Sea (HELCOM, 2010) were used for benthic and pelagic habitats and communities as well as supporting indicators. Detailed

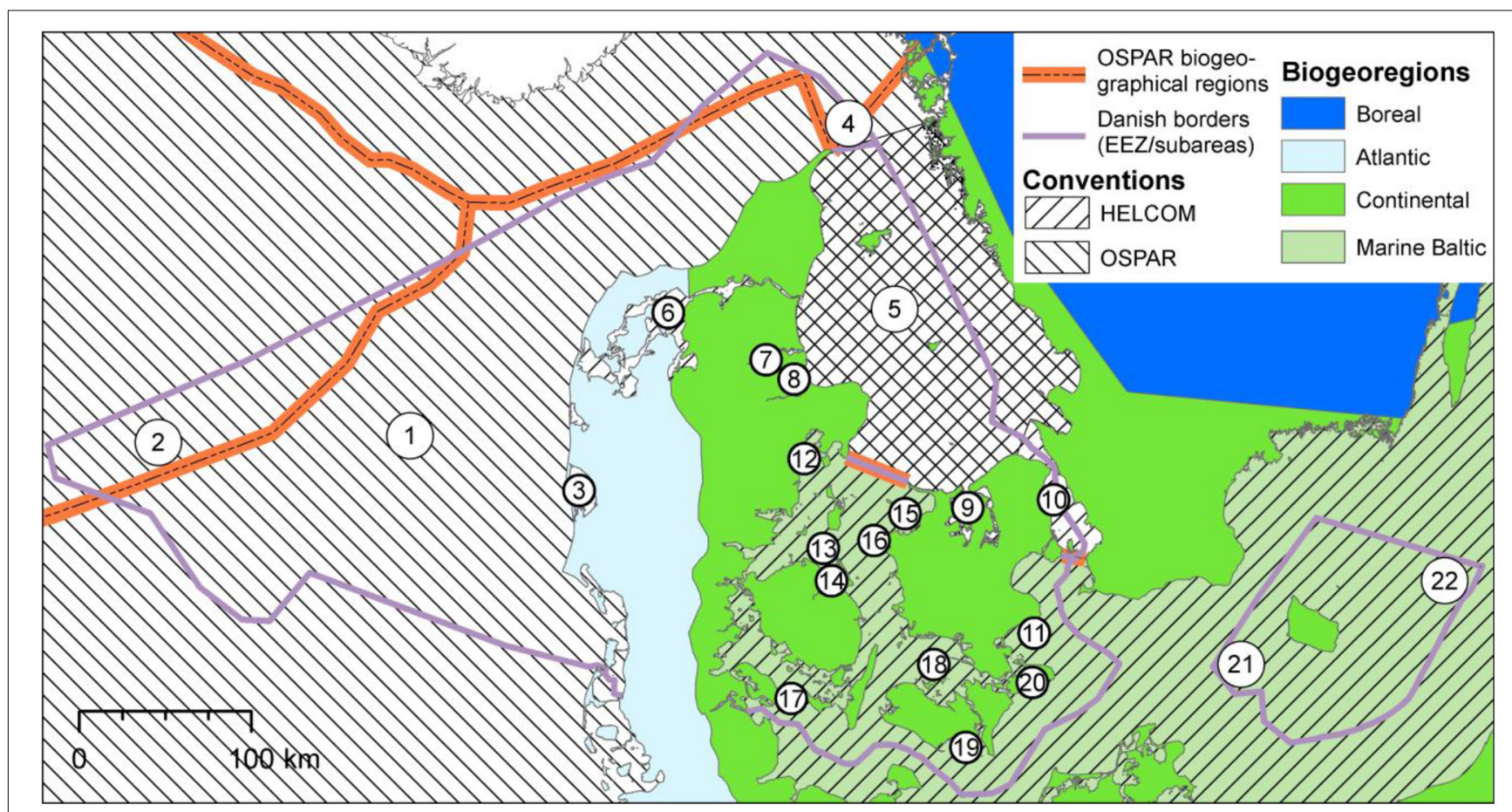

FIGURE 1 | Map of Danish marine waters. The borders indicated in the map represent the current MSFD boundary between the North Sea region and the Baltic Sea region, relevant OSPAR boundaries, relevant HELCOM boundaries as well as relevant Habitats Directive boundaries for biogeographical regions (BOR, Boreal; ATL, Atlantic; CON, Continental). Numbers indicates assessment sectors (see Table 1 for names). Large circles indicate offshore assessment sectors, small circles coastal assessment sectors. 
Table 1 | Assessment and classification of biodiversity status in Danish marine waters.

\begin{tabular}{|c|c|c|c|c|c|}
\hline Assessment sector & \multicolumn{4}{|c|}{ Biodiversity Quality Ratio (BOR) } & $\begin{array}{l}\text { Integrated } \\
\text { assessment }\end{array}$ \\
\hline 2. NORTH SEA, northern parts & 0.700 & 0.904 & $0.619^{*}$ & - & SI \\
\hline 3. Ringkøbing Fjord & - & $0.377^{*}$ & - & 0.850 & SI \\
\hline 4. SKAGERRAK, open parts & 0.862 & 0.939 & $0.502^{*}$ & - & $\mathrm{SI}$ \\
\hline 7. Mariager Fjord & - & - & $0.370^{*}$ & 0.519 & SI \\
\hline 8. Randers Fjord & 0.562 & $0.258^{*}$ & 0.485 & 0.369 & $\mathrm{SI}$ \\
\hline 9. Isefjorden/Roskilde Fjord & - & $0.613^{*}$ & - & 0.763 & SI \\
\hline 10. The Sound, central parts & $0.525^{*}$ & 0.823 & - & 0.560 & $\mathrm{MO}$ \\
\hline 11. Fakse Bight/Stevns & 0.843 & 0.704 & - & $0.336^{*}$ & $\mathrm{SI}$ \\
\hline 15. Sejerø Bight & - & $0.443^{*}$ & - & - & SI \\
\hline 16. Kalundborg Fjord & - & $0.357^{*}$ & - & - & $\mathrm{SI}$ \\
\hline 17. Lillebælt, southern parts & $0.230^{*}$ & 0.541 & - & 0.500 & SI \\
\hline 18. Smålandsfarvandet & - & $0.513^{*}$ & - & - & SI \\
\hline 19. Rødsand & - & $0.590^{*}$ & - & - & $\mathrm{SI}$ \\
\hline 20. Hjelm Bight & 0.838 & 0.702 & - & $0.533^{*}$ & SI \\
\hline 21. ARKONA BASIN & $0.534^{*}$ & 0.764 & 0.566 & 0.616 & $\mathrm{MO}$ \\
\hline 22. BORNHOLM BASIN & 0.553 & $0.239 *$ & 0.566 & 0.604 & SI \\
\hline Offshore assessment sectors (average) & 0.601 & 0.750 & 0.565 & 0.651 & - \\
\hline Coastal assessment sectors (average) & 0.522 & 0.534 & 0.428 & 0.540 & - \\
\hline
\end{tabular}

For each assessment sector, the weighted Biodiversity Quality Ratio (BQR) is presented. These values represent the perturbation in regard to the reference conditions. C I, marine landscapes (broad-scale marine habitats); C II, communities; C III, species; C IV, supporting indicators; MO, moderately affected by human activities; and SI, significantly affected by human activities. The category being decisive for the outcome of the integrated assessment and classification is marked with an asterisk. See Online Supporting material for details.

information about (1) the interim biodiversity indicators, (2) the sources for the monitoring data used as well as (3) the periods covered is available online as Supporting Material.

\section{RESULTS}

The average number of indicators per assessment sector was 10.2 $(n=22)$ ranging from 1 (no. 15 and 16) to 25 (no. 5). The average number of indicators in the four categories I-IV was 1.0, 4.0, 3.1, and 2.3, respectively. For the 6 offshore assessment sectors, the average number of indicators was 19.3 ranging from 8 (no. 22) to 25 (no. 2 and 5) and the average number of indicators in the four categories were $1.5,5.8,10.3$, and 1.8 respectively. For the remaining 16 coastal assessment sectors, the average number of indicators was 6.8 ranging from 1 (no. 15 and 16) to 15 (no. 6) and the average number in the four categories were $0.9,3.3,0.3$, and 2.4 , respectively.

In the Danish marine waters, the average Biological Quality Ratio was $0.556,0.595,0.531$, and 0.563 per category (Table 1 ). In category I, the BQR ranged from 0.230 to 0.862 , in category II from 0.239 to 0.939 , in category III from 0.370 to 0.656 , and in category IV from 0.320 to 0.850 .
For each assessment sector, a status classification was made per category and combined to a final integrated assessment of status per assessment sector (Table 1). The average of the lowest classified category was 0.433 , ranging from 0.230 (sector 17: Southern Little Belt) to 0.639 (sector no. 1: North Sea, East+South). Areas with a BQR $<0.400$ included Odense Fjord (sector 14), Little Belt (sector 17), and Bornholm Basin (sector 22), which all are significantly affected by eutrophication (HELCOM, 2010; Andersen et al., 2011). Areas with a $B Q R$ value above 0.600 were few and only found in the North Sea (sectors no. 1 and 2) and Isefjorden/Roskilde Fjord (sector 9). None of the assessment sectors were classified as unaffected by human activities. Three out of 22 assessment sectors were classified as moderately affected by human activities. The areas were Arkona Basin (no. 21), The Sound (no. 10) and Aarhus Bight (no. 12). The remaining $19 \mathrm{sec}-$ tors were classified as significantly affected by human activities, and in 17 of these, the final classification was caused by categories I (broad-scale habitats), II (communities) or III (species). In two sectors, Hjelm Bight (no. 20) and Fakse Bight/Stevns (no. 11), the final classifications were a result of supporting indicators. 
The confidence of the assessments was generally estimated to be above $50 \%$ and therefore considered acceptable (Figure $2 \mathrm{~A}$ ). However, two assessment sectors had a low confidence (no. 15 and 16: respectively, Sejerø Bay and Kalundborg Fjord) due to low number of indicators in the assessment in combination with challenges in regard to the setting of AcDev. Analysing the data per indicator revealed that monitoring data (State) and RefCon values on average had a higher confidence than the information on AcDev, which seemed to be slightly below the border between acceptable and low confidence (Figure 2). Scrutiny of the confidence per category revealed that all four categories on average had an acceptable confidence. All final classifications of the biodiversity status in the North Sea/Skagerrak area and the Kattegat had an acceptable confidence, while in the sub-division covering the Danish parts of the Baltic Sea, 2 out of 12 had an unacceptable confidence.

\section{DISCUSSION}

In this study we have presented a spreadsheet-based assessment tool for assessment of biodiversity, based on indicators, quantitative thresholds for good environmental status, and confidence rating. The assessment tool, tested by using both (i) existing and provisional indicators and (ii) recent data, showed that the marine biodiversity of Danish marine waters cannot be considered to be in good environmental status. The perturbations from reference conditions are indicative of human pressures in the assessment area (OSPAR, 2010; Korpinen et al., 2012).

Given the data and indicators available, we estimated the perturbations-understood as the deviation from reference conditions-represented by the lowest $\mathrm{BQR}$ values within an assessment sector. Parts of the North Sea and Skagerrak were less disturbed compared to the Kattegat and the Danish parts of the Baltic Sea (Figure 3A). The areas deviating most from reference conditions are all characterized by high nutrient inputs, high fishing pressure, and physical modification, sometimes caused by destructive fishing practices (HELCOM, 2010; Korpinen et al., 2012). Any measures to improve biodiversity status should as a priority address these key pressures.

An overview of the biodiversity status in the Danish marine waters revealed that a group of sectors being classified as moderately affected are interconnected (Figure 3B). The Sound is located downstream of Arkona Basin with a surface current from Arkona Basin to the west through Femernbelt between Denmark and Germany and to the north through the Sound. Hjelm Bight (sector no. 20) is located to the west and downstream of Arkona Basin. Fakse Bight/Stevns (sector no. 11) is located in between Arkona Basin and the Sound. The biodiversity status of the Arkona Basin and the Sound being classified as moderately affected by human activities is in line with the general understanding of the ecological status of these areas (HELCOM, 2010). Another sector having a slightly better status is Aarhus Bight (no. 12), where biodiversity status was classified as moderately affected by human activities in all the four categories. This, together with an estimated high confidence, does in our opinion confirm the classification. The reason for this slightly better status compared to adjacent sectors is most likely due to significant reductions in nutrient loads to Arhus Bight over past two decades (HELCOM, 2012).
Making an assessment without estimating the confidence of the result is a tendency, which in principle is unacceptable (Figure 3C). Estimating confidence is a statistical challenge, but the simple scoring system developed as a part of BEAT 2.0 overcomes this challenge in a non-statistical way and is able to cover confidence of threshold values, data and also the low number of indicators. This approach can be seen as temporary, leading to more sophisticated and data driven systems for assessment of confidence.

Many of the indicators in this assessment test have long traditions in previous assessments. Benthic communities and submerged aquatic vegetation have a long history in regard to assessments of eutrophication in the North Sea and Baltic Sea regions. Also indicators of fish communities have been used in previous assessments (Daan et al., 2005; Greenstreet et al., 2011), but reference levels had not yet been proposed for our study area, and for this analysis we used reference levels and acceptable deviations of 1 standard deviation based on the historic time series available.

Basin-wide biodiversity assessments have not hitherto included indicators for seabirds or marine mammals. The assessment in this respect can therefore be seen as a first attempt to use the trends in the population size of key species of seabirds or marine mammals as indicators of the status of the pelagic ecosystem in terms of habitat quality, food supply, and human-induced displacement. As the seabird data available for the assessment did not include data from the most recent period, the assessment used AcDev values of 50\% and, hence, may give false positive impression of their status. Therefore, the reported changes in the abundance of fish-eating seabirds in the eastern parts of the North Sea, Skagerrak, and Kattegat should be regarded as strong indications of negative changes in the ecological status of these regions. Recent studies indicate that the regional reduction of fish-eating seabirds in the North Sea is mainly governed by changes in the large-scale abundance of herring (Fauchald et al., 2011). Reflecting the spatial caveats in the marine mammal data, the assessment used AcDev values of $50 \%$. It is not known to what degree the impaired status of marine mammals in the eastern parts of the North Sea is a result of similar changes in the supply of pelagic fish which affected the abundance of seabirds in these regions. We did not include indicators for non-native species in this study. However, there is a growing understanding that, contrary to the normally negative perception of the ecological impact of non-native species, some species may provide significant ecosystem services in specific cases (Norkko et al., 2012).

In the current implementation process of the EU MSFD, there is a growing need to coordinate indicator development and agree on common sets of indicators, which allow coherent, trans-boundary assessments of the state of marine environment. By using existing indicators from the region, we noticed that several of the indicators were inherently correlated in nature (e.g., LFI and the slope of the size spectra, or chlorophyll a and Secchi depth) and using both as independent indicators in the present study may not be appropriate from a statistical point of view. In this study this correlation was accounted for by giving small weights to such indicators, but more stringent statistical 


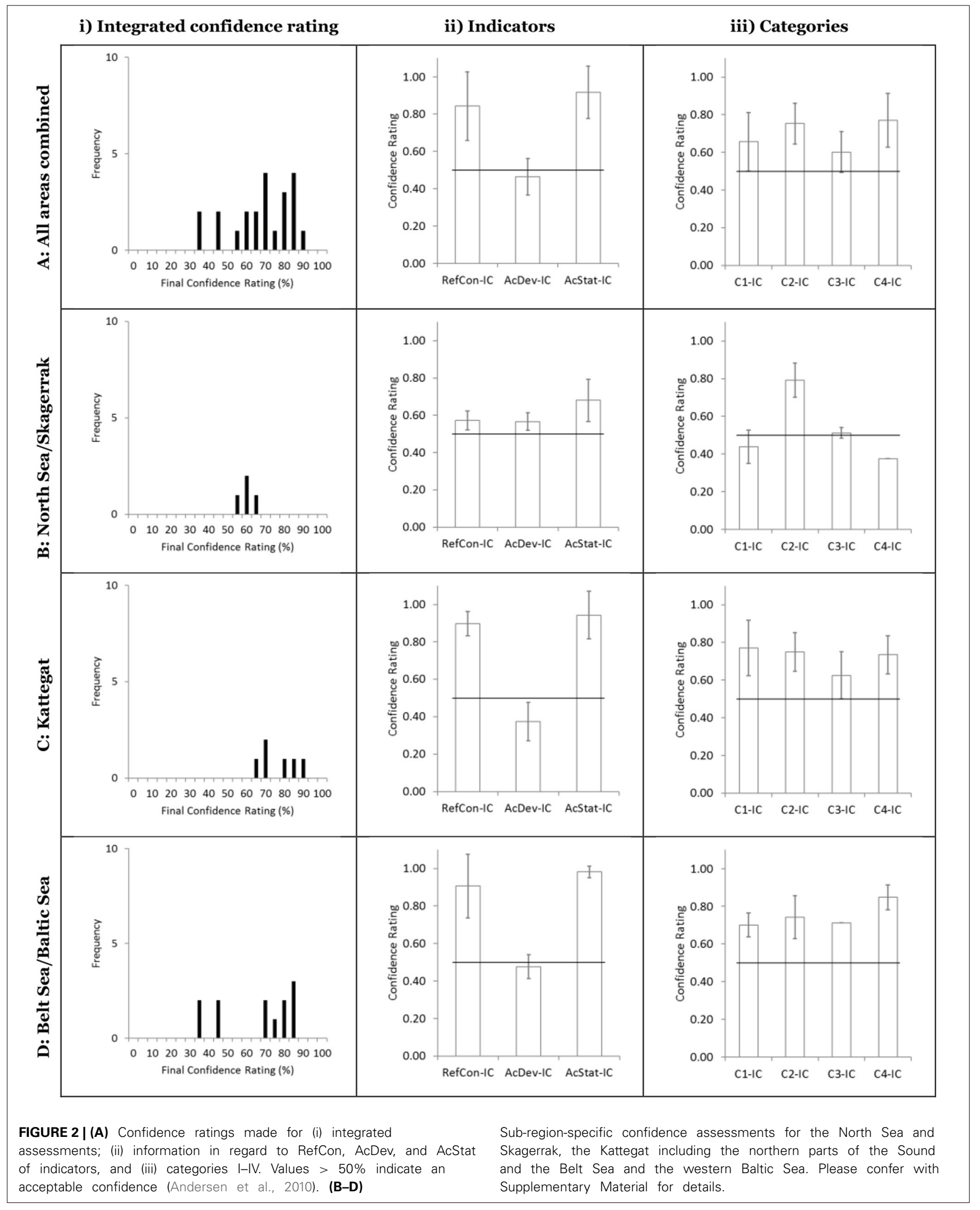



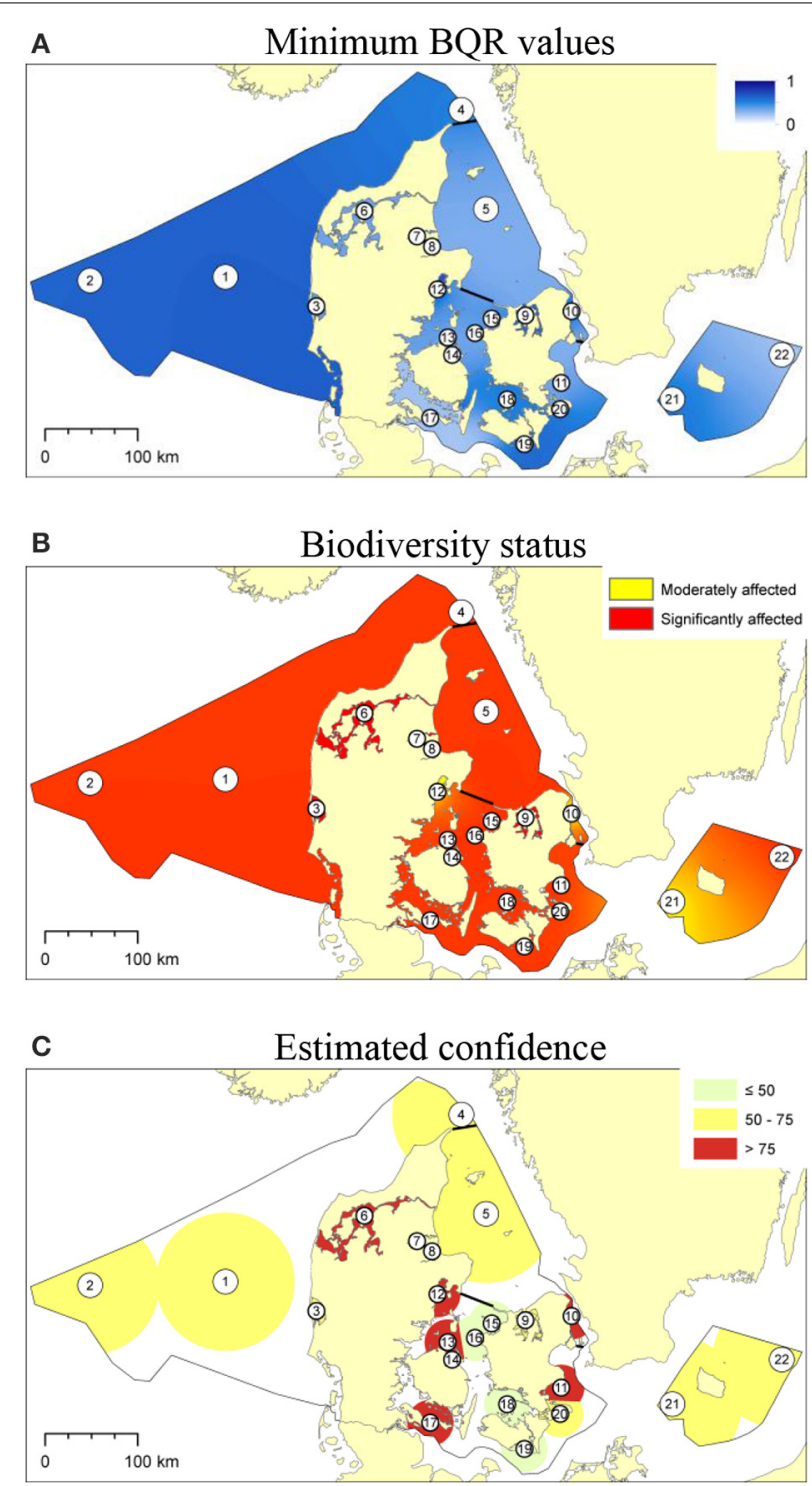

FIGURE 3 | Spatial distribution of BOR's (A), biodiversity status (B), and the estimated confidence (C). For illustration purposes representative points were chosen to represent the assessment sectors. From these points the results were spread to the marine area using a spline with barriers technique. For the six closed fjords (sectors 3, 6-9, 14) the values were spread evenly over the whole fjord. in bottom waters (Conley et al., 2000; Nielsen et al., 2002a,b; Carstensen et al., 2004; Dahl and Carstensen, 2008). Thus, the water quality indicators can in a sense be called "true" indicators, as they can predict biological changes with simple methodology and relatively low costs. Nonetheless, in this study we considered them as "indirect" and prefer more direct measurements of biological parameters.

\section{CONCLUDING REMARKS}

Biological diversity in the Danish marine waters is significantly affected by human activities in most areas, but in a few sectors only moderately. None of the assessed sectors were classified as having a biodiversity status unaffected by human activities. The confidence of the assessments was estimated indirectly and generally regarded as acceptable, in a few cases even high. In two out of 22 sectors, the confidence was low indicating that monitoring of biodiversity in these sectors should be improved. The majority of the indicators were considered scientifically robust, but some indicators could, however, be further strengthened through production of peer reviewed scientific publications. Caution is also recommended in regard to the use of supporting indicators, especially in those few cases where they overrule biological indicators and thus determine the outcome of the integrated and final classification of biodiversity status. The BEAT 2.0 tool can support the EU Member States in the implementation of the MSFD, which specifically requires an overall assessment of the state of the marine environment as well as a specific assessment of biodiversity (Anon, 2008). The tool requires reliable indicators and quantitative thresholds for GES, but can function even with heterogeneous data availability. Assessments based on single indicators, though being simpler to link to human pressures, cannot reflect the variability and complexity of biodiversity responses required by the new assessments and therefore an integration of several indicators by an assessment tool is a prerequisite for the successful interface of science and environmental policy.

Finally, we would prudently like to remind the reader that there is no such thing as a perfect assessment tool. We do not promote the BEAT tool as such. We rather see this tool as a step for further development leading to better ecosystem-based tools for assessment, classification and adaptive management of marine biodiversity and human activities affecting marine life. The key challenges in regard to future integrated assessments of biodiversity status in marine waters are: (1) development of a wider range of biodiversity indicators representing different ecosystem components/food web categories, as well as (2) development of data driven methods for indicator integration and estimation of uncertainties.

\section{ACKNOWLEDGMENTS}

This article has been funded by the HARMONY project. The article has also been supported by the DEVOTES (DEVelopment Of innovative Tools for understanding marine biodiversity and assessing good Environmental Status) project funded by the European Union under the 7th Framework Programme, "The Ocean of Tomorrow" Theme (grant agreement no. 308392), www.devotes-project.eu. The authors would like to thank Johnny Reker and Joachim Raben as well as Stefan Heinänen, Alf B. 
Josefson, Alf Norkko, and Anna Villnäs. Martin Hartvig acknowledges the Danish National Research Foundation for support to the Center for Macroecology, Evolution and Climate. A prototype of the BEAT assessment tool was originally developed for HELCOM's integrated thematic assessment of biodiversity in the Baltic Sea and we would like to thank Hermanni Backer, Maria Laamanen, and Ulla Li Zweifel for constructive discussions of this prototype.

\section{SUPPLEMENTARY MATERIAL}

The Supplementary Material for this article can be found online at: http://www.frontiersin.org/journal/10.3389/fmars. 2014.00055/abstract

Additional supplementary material, i.e., Annex S1 containing detailed information on data sources and provisional indicators used for the testing of the tool presented in this study, Annex S2 a summary of the confidence rating methodology, Annex S3 containing 22 individual BEAT classifications, and Annex S4 being a step-wise BEAT 2.0 tutorial, is available to the online version of this article.

\section{REFERENCES}

Ærtebjerg, G., Andersen, J. H., and Hansen, O.S. (2003). Nutrients and Eutrophication in Danish Marine Waters. A Challenge to Science and Management. National Environmental Research Institute. Available online at: http://www2.dmu.dk/1_Viden/2_Publikationer/3_ovrige/rapporter/Nedmw 2003_alle.pdf

Andersen, J. H., Axe, P., Backer, H., Carstensen, J., Claussen, U., Fleming-Lehtinen, V., et al. (2011). Getting the measure of eutrophication in the Baltic Sea: towards improved assessment principles and methods. Biogeochemistry 106, 137-156. doi: 10.1007/s10533-010-9508-4

Andersen, J. H., Murray, C., Kaartokallio, H., Axe, P., and Molvær, J. (2010). A simple method for confidence rating of eutrophication status classifications. Mar. Pollut. Bull. 60, 919-924. doi: 10.1016/j.marpolbul.2010.03.020

Anon. (2000). Directive 200/60/EC of the European Parliament and of the Council of 23 October 2000 establishing a framework for Community action in the field of water policy. Official J. Eur. Commun. L 327, 1-72.

Anon. (2008). Directive 2008/56/EC of the European Parliament and the Council of 17 June 2008 establishing a framework for community action in the field of marine environmental policy (Marine Strategy Framework Directive). Official J. Eur. Union Brussels L 164, 19-40.

Anon. (2010). Commission decision of 1 September 2010 on criteria and methodological standards on good environmental status of marine waters. Official J. Eur. Union L 232, 14-24.

Borja, A. (2014). Grand challenges in marine ecosystems ecology. Front. Mar. Sci. 1:1. doi: 10.3389/fmars.2014.00001

Borja, A., Elliott, M., Andersen, J. H., Carstensen, J., Ferreira, J. G., Heiskanen, A.-C., et al. (2013). Good Environmental Status of marine ecosystems: What is it and how do we know when we have attained it? Mar. Pollut. Bull. 76, 16-27. doi: 10.1016/j.marpolbul.2013.08.042

Cardoso, A. C., Cochrane, S., Doerner, H., Ferreira, J. G., Galgani, F., Hagebro, C., et al. (2010). Scientific Support to the European Commission on the Marine Strategy Framework Directive. Luxemburg: Management Group Report. European Commission, Joint Research Centre.

Carstensen, J., Conley, D. J., Andersen, J. H., and Aertebjerg, G. (2006). Coastal eutrophication and trend reversal: a Danish case study. Limnol. Oceanol. 51, 398-408. doi: 10.4319/lo.2006.51.1_part_2.0398

Carstensen, J., Conley, D. J., and Henriksen, P. (2004). Frequency, composition, and causes of summer phytoplankton blooms in a shallow coastal ecosystem, the Kattegat. Limnol. Oceanogr. 49, 190-201. doi: 10.4319/lo.2004.49.1.0191

Certain, G., Skarpaas, O., Bjerke, J.-W., Framstad, E., Lindholm, M., Nilsen, J.-E., et al. (2011). The nature index: a general framework for synthesizing knowledge on the state of biodiversity. PLOS ONE 6:e18930. doi: 10.1371/journal.pone. 0018930
Conley, D. J., Kaas, H., Møhlenberg, F., Rasmussen, B., and Windolf, J. (2000). Characteristics of Danish estuaries. Estuaries 23, 820-837. doi: 10.2307/1353000

Daan, N., Gislason, H., Pope, J. G., and Rice, J. C. (2005). Changes in the North Sea fish community: evidence of indirect effects of fishing? ICES J. Mar. Sci. 62, 177-188. doi: 10.1016/j.icesjms.2004.08.020

Dahl, K., and Carstensen, J. (2008). Tools to Assess Conservation Status on Open Water Reefs in Nature-2000 Areas. NERI Technical Report No. 663. National Environmental Research Institute, University of Aarhus. Available online at: http://www.dmu.dk/Pub/FR663.pdf

Fauchald, P., Skov, H., Skern-Mauritzen, M., Hausner, V. H., Johns, D., and Tveraa, T. (2011). Scale-dependent response diversity of seabirds to prey in the North Sea. Ecology 92, 228-239. doi: 10.1890/10-0818.1

Greenstreet, S., Rogers, S., Rice, J., Piet, G., Guirey, E., Fraser, H., et al. (2011). Development of the EcoQO for the North Sea fish community. ICES J. Mar. Sci. 68, 1-11. doi: 10.1093/icesjms/fsq156

Hansen, J. W. (2013). Marine områder 2012. NOVANA. Tilstand og udvikling i miljøog naturkvaliteten. Aarhus Universitet, DCE - Nationalt Center for Miljø og Energi. 162 s. Videnskabelig rapport fra DCE - Nationalt Center for Miljø og Energi nr. 77. (In Danish)

HELCOM. (2009a). "Biodiversity in the Baltic Sea - An integrated thematic assessment on biodiversity and nature conservation in the Baltic Sea," in Baltic Sea Environment Proceedings 116B (Helsinki: Helsinki Commission), 188.

HELCOM. (2009b). "Eutrophication in the Baltic Sea. An integrated thematic assessment of eutrophication in the Baltic Sea region," in Baltic Sea Environmental Proceedings No. 115B (Helsinki: Helsinki Commission), 148.

HELCOM. (2010). "Ecosystem health of the Baltic Sea 2003-2007. HELCOM initial holistic assessment," in Baltic Sea Environment Proceedings 120 (Helsinki), 63.

HELCOM. (2012). "Fifth Baltic Sea Pollution Load Compilation (PLC-5)" in Baltic Sea Environment Proceedings 128 (Helsinki: Helsinki Commission), 217.

Korpinen, S., Meski, L., Andersen, J. H., and Laamanen, M. (2012). Human pressures and their potential impact on the Baltic Sea ecosystem. Ecol. Indic. 15, 105-114. doi: 10.1016/j.ecolind.2011.09.023

Nielsen, S. L., Sand-Jensen, K., Borum, J., and Geertz-Hansen, O. (2002a). Depth colonisation of eel-grass (Zostera marina) and macroalgae as determined by water transparency in Danish coastal waters. Estuaries 25, 1025-1032. doi: 10.1007/BF02691349

Nielsen, S. L., Sand-Jensen, K., Borum, J., and Geertz-Hansen, O. (2002b). Phytoplankton, nutrients and transparency in Danish coastal waters. Estuaries 25, 930-937. doi: 10.1007/BF02691341

Norkko, J., Reeds, D. C., Timmerman, K., Norkko, A., Gustafsson, B. G., Bonsdorff, E., et al. (2012). A welcome can of worms? Hypoxia mitigation by an invasive species. Global Change Biol. 18, 422-434. doi: 10.1111/j.1365-2486.2011.02513.x

Ojaveer, H., and Eero, M. (2011). Methodological challenges in assessing the environmental status of a marine ecosystem: case study of the baltic sea. PLoS ONE 6:e19231. doi: 10.1371/journal.pone.0019231

Ojaveer, H., Jaanus, A., MacKenzie, B. R., Martin, G., Olenin, S., Radziejewska, T., et al. (2010). Status of biodiversity in the Baltic Sea. PLOS ONE 5:e12467. doi: 10.1371/journal.pone.0012467

OSPAR. (2010). Quality Status Report 2010. London: OSPAR Commission.

Conflict of Interest Statement: The authors declare that the research was conducted in the absence of any commercial or financial relationships that could be construed as a potential conflict of interest.

Received: 04 April 2014; accepted: 30 September 2014; published online: 29 October 2014.

Citation: Andersen JH, Dahl K, Göke C, Hartvig M, Murray C, Rindorf A, Skov H, Vinther $M$ and Korpinen $S$ (2014) Integrated assessment of marine biodiversity status using a prototype indicator-based assessment tool. Front. Mar. Sci. 1:55. doi: 10.3389/ fmars.2014.00055

This article was submitted to Marine Ecosystem Ecology, a section of the journal Frontiers in Marine Science.

Copyright (C) 2014 Andersen, Dahl, Göke, Hartvig, Murray, Rindorf, Skov, Vinther and Korpinen. This is an open-access article distributed under the terms of the Creative Commons Attribution License (CC BY). The use, distribution or reproduction in other forums is permitted, provided the original author(s) or licensor are credited and that the original publication in this journal is cited, in accordance with accepted academic practice. No use, distribution or reproduction is permitted which does not comply with these terms. 